\title{
Inclusão Digital para adultos: Relato de experiência
}

\author{
Fernanda Corrêa Garcia ${ }^{1}$, Felipe Schneider Costa ${ }^{2}$, \\ Diego Ramos Gomes ${ }^{3}$, Rebeca Guedes M. da Silva ${ }^{4}$
}

\begin{abstract}
Resumo: Este artigo apresenta o relato de experiência do projeto de extensão Inclusão Digital para Adultos. O projeto teve como objetivo principal desenvolver a inclusão digital do educando, fazendo com que, após sua inserção no mundo digital, ele possa interagir com esse novo paradigma social, sentindo-se valorizado como indivíduo, realizando-se como profissional, contribuindo, assim, para a melhoria de seu contexto social, de acordo com a formação obtida. O projeto foi posto em prática através de oficinas educativas nas quais o público adulto foi atendido. Esta atividade também contribuiu para a aproximação da comunidade externa com o Instituto Federal de Santa Catarina - campus Tubarão. Ao final do projeto conclui-se que os objetivos foram alcançados. No total, foram atendidos 30 alunos.
\end{abstract}

Palavras-chave: Inclusão digital. Oficinas práticas. Comunidade externa. IFSC.

Área Temática: Políticas Públicas.

\section{Digital Inclusion for adults: Experience report}

Abstract: This article presents the experience report of the Digital Inclusion for Adults extension project. The main objective of the project was to develop the digital inclusion of the student, making it possible, after entering the digital world, to interact with this new social paradigm, feeling valued as an individual, performing as a professional, thus contributing to for the improvement of their social context, according to the training obtained. The project was made possible through educational workshops in which the adult audience was served. This activity also contributed to bringing the external community closer to the Federal Institute of Santa Catarina-Tubarão campus. At the end of the project it is concluded that the objectives have been achieved. In total, 30 students were served.

Keywords: Digital inclusion. Practical workshops. External community. IFSC.

\section{Inclusión digital para adultos: Informe de experiencia}

Resumen: Este artículo presenta el relato de experiencia del proyecto de extensión Inclusión Digital para Adultos. El objetivo principal del proyecto fue desarrollar la inclusión digital del alumno, posibilitando, luego de su inserción en el mundo digital, interactuar con este nuevo paradigma social, sintiéndose valorado como individuo, desempeñándose como profesional, contribuyendo así a para la mejora de su contexto social, de acuerdo con la formación obtenida. El proyecto fue posible a través de talleres educativos en los que se consideró al público adulto. Esta actividad también contribuyó a acercar la comunidad externa al Instituto Federal de Santa Catarina - campus Tubarão. Al final del proyecto se concluye que se han alcanzado los objetivos. En total, se atendió a 30 estudiantes.

Palabras clave: Inclusión digital. Talleres prácticos. Comunidad externa. IFSC.

${ }^{1}$ Mestre em Educação Profissional e Tecnológica, Técnica em Assuntos Educacionais no campus Tubarão do Instituto Federal de Santa Catarina (IFSC)

${ }^{2}$ Mestre em Ciência da Computação pela Universidade Federal de Santa Catarina (UFSC), professor EBTT no campus Tubarão do Instituto Federal de Santa Catarina - IFSC

${ }^{3}$ Discente do curso superior em Análise e Desenvolvimento de Sistemas no campus Tubarão do Instituto Federal de Santa Catarina - IFSC

${ }^{4}$ Discente egressa curso técnico em Informática do campus Tubarão Instituto Federal de Santa Catarina - IFSC 


\section{INTRODUÇÃO}

A inclusão digital ainda é um desafio para o Brasil, principalmente entre a população de menor poder aquisitivo. A pesquisa sobre o uso das Tecnologias de Informação e Comunicação nos domicílios brasileiros (TIC Domicílios 2016) apontou que mais de 35 milhões de domicílios das classes Ce D não possuem computadore desses, aproximadamente 30 milhões não estão conectados à internet, o que representa mais da metade do total de domicílios brasileiros. Em março de 2017, um estudo da The Economist Intelligence Unit em parceria com o Facebook apontou que cerca de 70 milhões de brasileiros não têm acesso à internet (THE ECONOMIST, 2017).

Conforme Assmann (2000, p. 9), as políticas públicas podem fazer a diferença, de modo a favorecer o crescimento de uma sociedade da informação onde todos tenham acesso aos novos serviços e aplicações das tecnologias digitais. Assim, "a democratização do acesso às tecnologias digitais de informação e comunicação deveria ser vista como elemento fundamental nas políticas de inclusão social” (FREIRE, 2012, p.192). Ademais, Assmann (2000, p. 9) insiste na necessidade de que possam ajudar as populações economicamente carentes a se beneficiarem das vantagens do progresso tecnológico, promovendo "o acesso universal à info-alfabetização e à info-competência" de modo a reforçar o caráter democrático da sociedade da informação.

A inclusão digital está ligada ao pensamento de Paulo Freire (1996), porque busca apresentar o uso da internet para auxiliar nas tarefas do cotidiano, aproximando a inserção das pessoas mais vulneráveis socialmente em relação as pessoas com maior poder aquisitivo. $O$ processo de inclusão vincula-se às condições de acesso à internet, ou seja, a exclusão digital amplia ainda mais a exclusão social.

Nesse sentido, e considerando também a inclusão digital como meio de inclusão social, o projeto de extensão Inclusão Digital para Adultos auxiliou e integrou adultos de 18 a 70 anos ao uso do computador e teve como objetivo geral desenvolver a inclusão digital do educando, fazendo com que após sua inserção no mundo digital ele possa interagir com esse novo paradigma social, sentindo-se valorizado como indivíduo, realizando-se como profissional, contribuindo assim para a melhoria de seu contexto social, de acordo com a formação obtida. Nesse sentido, Lazarte afirma:

A forma de se proporcionar este acesso deve estar integrada às condições locais existentes, em termos de suas organizações, tanto quanto em seus referenciais culturais. Centros de produção, criação e compartilhamento cultural (e de acesso à rede) devem estar integrados a associações comunitárias, centros religiosos, igrejas etc. (LAZARTE, 200, p. 48).

O projeto, aprovado pelo edital de Fluxo Contínuo 2017 da Pró-Reitoria de Extensão e Relações Externas (PROEX) do Instituto Federal de Santa Catarina - IFSC, teve duração entre os meses de agosto e dezembro de 2017; incluindo planejamento, divulgação e execução das oficinas práticas direcionadas à área de tecnologia, as quais foram realizadas com o intuito de viabilizar a inclusão digital do público adulto, contribuindo assim para a aproximação entre a comunidade externa e o IFSC. 


\section{METODOLOGIA}

As atividades foram realizadas nas dependências do Instituto Federal de Santa Catarina - IFSC campus Tubarão, com a atuação de um docente do eixo Informação e Comunicação, um membro da coordenação e dois alunos bolsistas que auxiliaram nos processos de elaboração, divulgação, inscrições, até a ministração e monitoria das oficinas. O projeto teve como público-alvo adultos de 18 a 70 anos que possuíam conhecimento limitado ou inexistente sobre o uso do computador. A turma foi composta por 19 participantes do sexo feminino e 11 do sexo masculino, todos residentes em cidades da região da Associação dos Municípios da região de Laguna-AMUREL.

Nos dois primeiros meses, ocorreram reuniões para elaboração do projeto, planejamento das oficinas; envolvendo conteúdo, metodologia e didática. Houve um período para busca ativa do público-alvo com fôlder no comércio local, flyer para a internet, divulgação em rádio, em escolas da região e no próprio campus. O projeto ofertou trinta vagas, sendo que todas foram preenchidas, havendo ainda lista de espera. As pré-inscrições foram realizadas na secretaria do campus. O professor-orientador disponibilizou um plano de ensino e um cronograma de aulas, direcionando os conteúdos a serem ministrados nas oficinas pelos bolsistas.

Nos três meses subsequentes foram realizadas as oficinas práticas no laboratório de informática do campus, com frequência de duas vezes por semana no período matutino, sendo três horas diárias e totalizando uma carga horária de setenta horas. O projeto levou em conta o contexto social e atuação profissional dos participantes, a fim de que conhecessem nas oficinas os princípios básicos do computador, desde como ligá-lo até o trabalho com editores de texto, gerenciamento de arquivos, navegação na internet, dentre outros.

\section{RESULTADOS E DISCUSSÃO}

A demanda pela realização das oficinas práticas ao público adulto com idade mais avançada se apresentou diante da observação de frequentes solicitações da comunidade por cursos de inclusão digital. Como a missão da instituição visa "promover a inclusão e formar cidadãos, contribuindo para o desenvolvimento socioeconômico e cultural" (IFSC, 2020), foi de grande valia a realização das atividades para esse público específico. Considerando que um dos eixos tecnológicos de atuação do campus Tubarão é o da Comunicação e Informação, o projeto visou proporcionar a inclusão desta parcela da população que não possui ou possui pouco acesso à tecnologia. A proposta de realização de oficinas à comunidade externa, com a monitoria de dois alunos, deu oportunidades educacionais de acesso a processos de formação e qualificação desde o nível básico, além de favorecer a troca e ampliação de conhecimentos entre monitores e participantes.

A coordenação geral do projeto, realizada pela Técnica em Assuntos Educacionais do campus, contou também com a orientação de um professor do eixo de Comunicação e Informação, que possui experiência no trabalho de inclusão desse público, mais especificamente com os alunos do Programa Nacional de Integração da 
Educação Profissional com a Educação Básica na Modalidade de Educação de Jovens e Adultos - PROEJA do campus Tubarão. Foram selecionados dois alunos bolsistas do Curso Técnico Concomitante em Informática para atuarem no planejamento e na monitoria dos alunos.

\begin{tabular}{|c|c|c|}
\hline & & 2. CONTEUUDO PROGRAMATTCO \\
\hline DATA & LOCAL & DESCRIÇÄO \\
\hline $12 / 09$ & $\begin{array}{l}\text { Laboratório } \\
\text { Informática - } \\
\text { Sala } 12\end{array}$ & $\begin{array}{l}\text { Acolhimento: } \\
\text { ¿Apresentação do Câmpus, do Curso, dos Alunos, dos Monitores e dos Professores } \\
\text { ¿ Videos (Força do Grupo, Atitude é tudo) } \\
\text { ¿Discussão } \\
\text { ¿-Atividade com teclado (typingstudy.com/pt/) }\end{array}$ \\
\hline $14 / 09$ & $\begin{array}{l}\text { Laboratório } \\
\text { Informática- } \\
\quad \text { Sala } 12\end{array}$ & $\begin{array}{l}\text { Atividade com teclado (Digitação de palav ras para explorar recursos do teclado como } \\
\text { maiúsculas, teclas de função, apagar, tabulação, números, ...) } \\
\text { Atividade com mouse. Jogos: } \\
\text { - "Mouse Avoider": http://maniadejogos com/logos/Mouse+Avoider } \\
\text { - "Click Maze": http://maniadeiogos com/logos/Click+Maze } \\
\text { - Aplicativo Diego }\end{array}$ \\
\hline $19 / 09$ & $\begin{array}{l}\text { Laboratório } \\
\text { Informática - } \\
\quad \text { Sala } 12\end{array}$ & $\begin{array}{l}\text { Digitação de textos } \\
\text { ¿ Selecionar textos relevantes para que os alunos pratiquem a digitação. } \\
\text { - "Mouse Avoider": http://maniadejogos.com/iogos/Mouse+Avoider } \\
\text { - "Click Maze": http//maniadejogos com/iogos/Click+Maze } \\
\text { - Aplicativo Diego }\end{array}$ \\
\hline $21 / 09$ & $\begin{array}{l}\text { Laboratório } \\
\text { Informática - } \\
\text { Sala } 12\end{array}$ & $\begin{array}{l}\text { Conhecimento básico do Sistema Operacional } \\
\text { ¿-Parte 1: sistema de janelas. } \\
\text { OAtividade } \\
\text { Parte 2: sistema de arquivos. } \\
\text { - Atividade }\end{array}$ \\
\hline $26 / 09$ & $\begin{array}{l}\text { Laboratório } \\
\text { Informática- } \\
\quad \text { Sala } 12\end{array}$ & $\begin{array}{l}\text { Atividades: } \\
\text { ¿ Digitação de textos } \\
\text { ¿-Prática do Mouse (programa Diego) } \\
\text { ¿-Sistema de Janelas } \\
\text { - Sistema de arquivos }\end{array}$ \\
\hline $28 / 09$ & $\begin{array}{l}\text { Laboratório } \\
\text { Informática - } \\
\quad \text { Sala } 12\end{array}$ & $\begin{array}{l}\text { Oficina de produção de texto (editor de texto) } \\
\text { ¿ Formatar caracteres e parágrafos }\end{array}$ \\
\hline $03 / 10$ & $\begin{array}{l}\text { Laboratório } \\
\text { Informática - } \\
\text { Sala } 12\end{array}$ & $\begin{array}{l}\text { Oficina de produção de texto (editor de texto) } \\
\text { ¿Formação de layout (margens, colunas } \ldots \text { ) }\end{array}$ \\
\hline $05 / 10$ & $\begin{array}{l}\text { Laboratório } \\
\text { Informática - } \\
\text { Sala } 12\end{array}$ & $\begin{array}{l}\text { Oficina de produção de texto (editor de texto) } \\
\text { ¿nserir figuras } \\
\text { ¿Criar e formatar tabelas (Inserir legendas em tabelas, gráficos e figuras) } \\
\text { ¿Inserir gráficos } \\
\text { - Inserir rodanés e cabecalhos }\end{array}$ \\
\hline 10/10 & $\begin{array}{l}\text { Laboratório } \\
\text { Informática - } \\
\text { Sala } 12\end{array}$ & $\begin{array}{l}\text { Oficina para o uso da Internet. } \\
\text { - Introdução } \\
\text { ¿Navegadores } \\
\text { - Elementos do navegador }\end{array}$ \\
\hline $12 / 10$ & \begin{tabular}{|l|} 
Laboratório \\
Informática - \\
Sala 12 \\
\end{tabular} & $\begin{array}{l}\text { - Recursos pesquisa } \\
- \text { Transferência de dados da Internet para o Editor de Texto }\end{array}$ \\
\hline $17 / 10$ & $\begin{array}{l}\text { Laboratório } \\
\text { Informática - } \\
\quad \text { Sala } 12\end{array}$ & $\begin{array}{l}\text { Oficina para uso de Redes Sociais. } \\
\text { - e-mail } \\
\text { zFacebook } \\
\text { - Linkedin } \\
\text { - Twitter }\end{array}$ \\
\hline $19 / 10$ & $\begin{array}{l}\text { Laboratório } \\
\text { Informática - } \\
\text { Sala } 12\end{array}$ & $\begin{array}{l}\text { Oficina sobre segurança no computador e na Internet. } \\
\text { - Backup } \\
\text { - Antivirus } \\
\text { - Segurança na navegação na internet } \\
\text { - Segurança no uso de e-mails }\end{array}$ \\
\hline $24 / 10$ & $\begin{array}{l}\text { Laboratório } \\
\text { Informática - } \\
\text { Sala } 12\end{array}$ & $\begin{array}{l}\text { Oficina para utilização de software de apresentação de slides. } \\
\text {-Atividade "Minha empresa" - Parte } 1\end{array}$ \\
\hline $26 / 10$ & $\begin{array}{l}\text { Laboratório } \\
\text { Informática - } \\
\text { Sala } 12 \\
\end{array}$ & $\begin{array}{l}\text { Oficina para utilização de software de apresentação de slides. } \\
\text { - Atividade "Minha empresa" - Parte } 2\end{array}$ \\
\hline $31 / 10$ & $\begin{array}{l}\text { Laboratório } \\
\text { Informática - } \\
\text { Sala } 12\end{array}$ & $\begin{array}{l}\text { Oficina para utilização de software de apresentação de slides. } \\
\text {-Atividade "Minha empresa" - Parte } 3\end{array}$ \\
\hline $02 / 11$ & \begin{tabular}{|l|} 
Laboratório \\
Informática - \\
Sala 12 \\
\end{tabular} & $\begin{array}{l}\text { Oficina para de planilhas eletrônicas. } \\
\text { - Introdução } \\
\text {-Batalha Naval }\end{array}$ \\
\hline $07 / 11$ & $\begin{array}{l}\text { Laboratório } \\
\text { Informática - } \\
\text { Sala } 12\end{array}$ & $\begin{array}{l}\text { Oficina para de planilhas eletrônicas. } \\
\text { ¿ Exercícios com fómulas }\end{array}$ \\
\hline $09 / 11$ & \begin{tabular}{|c|} 
Laboratório \\
Informática - \\
Sala 12 \\
\end{tabular} & $\begin{array}{l}\text { Oficina para de planilhas eletrônicas. } \\
\text { ¿ Exercícios com fómulas }\end{array}$ \\
\hline $14 / 11$ & $\begin{array}{l}\text { Laboratório } \\
\text { Informática - } \\
\text { Sala } 12\end{array}$ & $\begin{array}{l}\text { Oficina para de planilhas eletrônicas. } \\
\text { - Exercícios com fómulas }\end{array}$ \\
\hline $16 / 11$ & \begin{tabular}{|c|} 
Laboratório \\
Informática - \\
Sala 12 \\
\end{tabular} & $\begin{array}{l}\text { Oficina para de planilhas eletrônicas. } \\
\text { ¿ Exercícios com formatação e gráficos }\end{array}$ \\
\hline
\end{tabular}

Figura 01 - Cronograma das oficinas.

Fonte: autores. 
O desenvolvimento das atividades permitiu aos bolsistas aprimorarem sua formação acadêmica e profissional. O envolvimento deles no processo de construção do projeto também permitiu a tomada de conhecimento das várias etapas envolvidas na construção de um projeto dentro de uma instituição pública. Outro ponto importante foi o envolvimento que os bolsistas tiveram com outros profissionais durante a execução das atividades. Além disso, como o objetivo elencado tem um forte apelo social, permitiu fortalecer nos bolsistas a importância de se pensar e de atuar em prol da cidadania, contribuindo para o desenvolvimento socioeconômico de comunidades e promovendo uma reflexão sobre os problemas sociais existentes.

Os bolsistas foram responsáveis pela execução das oficinas, junto a coordenação e orientação dos responsáveis pelo projeto. No início da execução das oficinas, a turma apresentou dificuldades com as atividades, já que tudo era muito novo para eles. Além disso, alguns estavam há bastante tempo afastados de uma sala de aula e, em alguns casos, não possuíam nenhum contato com a tecnologia da informação. Durante as aulas, foram apresentados os princípios básicos do computador, desde como ligá-lo até o trabalho com editores de texto, gerenciamento de arquivos (Figura 2), navegação na internet, dentre outros.

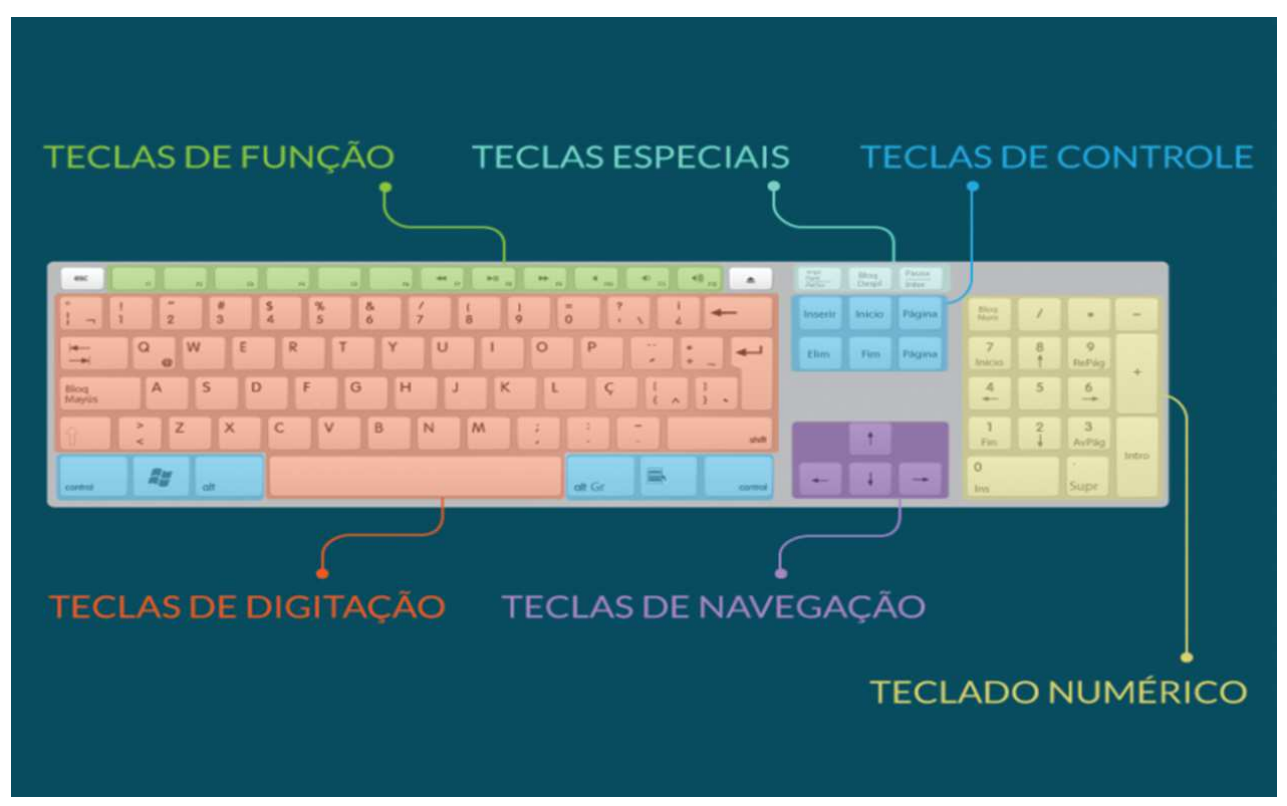

Figura 02 - Material Oficina prática.

Fonte: autores.

Na primeira oficina foram avaliados, por meio de formulário escrito e depoimentos dos alunos, o conhecimento prévio e a frequência que cada aluno utilizava os recursos tecnológicos. Após foram aplicadas com os alunos atividades práticas em teclado e mouse, para observar como eles se saiam. Foram executados exercícios desde criação de frases até jogos educativos para treinar os cliques no mouse. No decorrer das oficinas, foram apresentados para eles editores de texto, e algumas ferramentas que lhes auxiliariam quando eles fossem criar algum documento textual. No decorrer das atividades foi possível perceber que $50 \%$ da turma teve dificuldade em acompanhar os conteúdos. Para reverter esse cenário, foi fundamental a dedicação por parte dos monitores 
que ofereceram atendimento individualizado a cada participante. Alguns participantes conseguiram assimilar os conteúdos mais rapidamente e assim, ajudavam os demais, de forma colaborativa, conforme demonstra o depoimento de um dos bolsistas "Depois de algumas aulas, percebemos que diferente do que pensávamos, os alunos respeitavam nossas atitudes e colaboravam muito com as aulas, o que deu um certo conforto para nós bolsistas" (bolsista do projeto). A turma se mostrou bastante comprometida, assídua e interessada nos assuntos que foram ministrados em sala de aula.

Um dos bolsistas desenvolveu um software para auxílio nas dificuldades com o uso do mouse (Figura 3), no qual o aluno associa/move palavras com o mouse para formar pequenas frases. Todas as atividades e materiais utilizados foram planejados de acordo com as necessidades da turma.

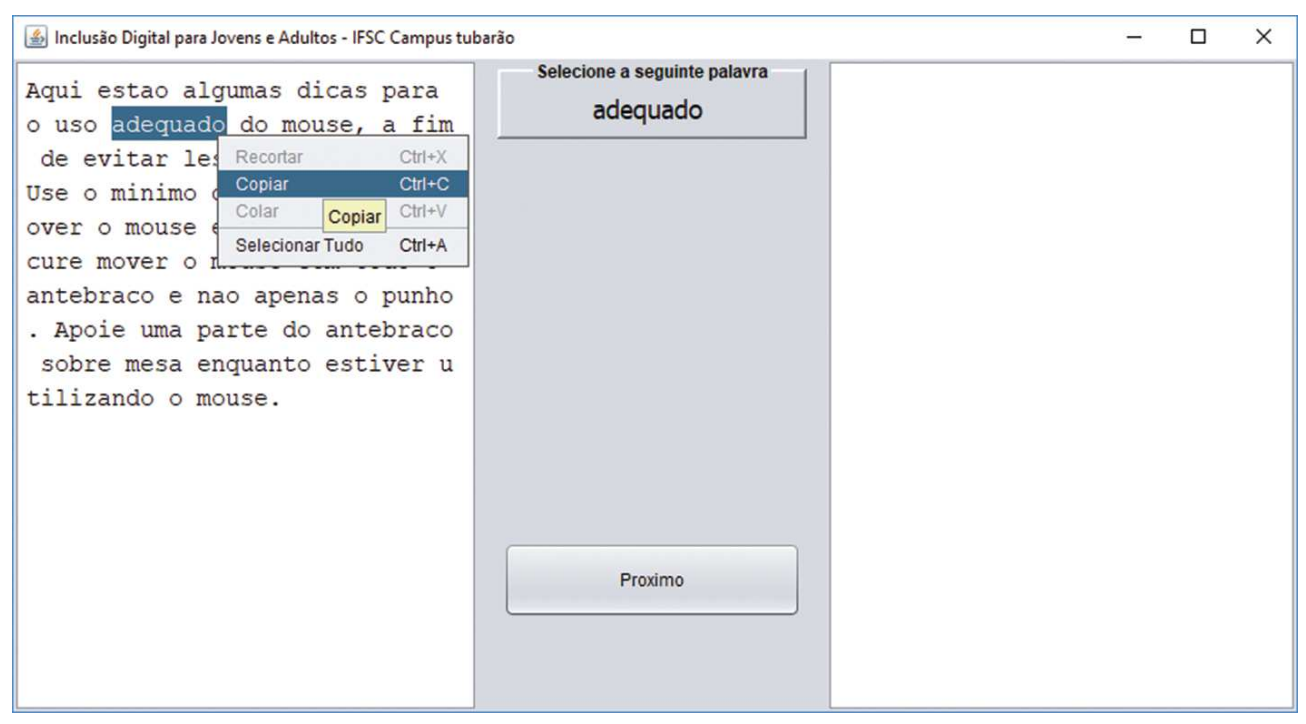

Figura 03 - Software desenvolvido pelo bolsista para propiciar o aprendizado do uso do mouse pelos alunos Fonte: autores.

Foi disponibilizado, também, o material impresso para estudos complementares em casa. O material continha o conteúdo aprendido na oficina, constando as exemplificações e o passo a passo para que o assunto fosse mais facilmente internalizado pelo aluno e praticado em casa. Além disso, os participantes que não tivessem meios para praticar, poderiam dirigir-se ao IFSC para utilizar os laboratórios de informática do campus. Também houve disponibilidade dos bolsistas para atendimento extraclasse aos participantes com dificuldades. Toda semana, eram propostas atividades diversificadas para esses alunos superarem os obstáculos do aprendizado. Com o decorrer do projeto, os bolsistas foram se adaptando à turma, compreendendo os perfis, realidades pessoais e ritmos de aprendizagem de cada um.

Houve mudança de postura por parte da equipe executora das oficinas, simplificação de nomenclaturas e instruções aos alunos para que a aprendizagem se desse de forma efetiva e significativa. Quando foi apresentado o assunto referente à navegação na internet, por exemplo, houve melhor assimilação dos conteúdos por parte da turma, visto que o uso das ferramentas do computador já estava eficiente. Foi realizada uma atividade, na qual os 
próprios alunos acessaram a internet para efetuar seu cadastro na plataforma SIGAA para, posteriormente, receberem seus certificados.

O método de avaliação durante todo o período de execução das oficinas foi processual e diagnóstico, a respeito da evolução e conhecimento de cada um dos alunos. Nas últimas semanas observou-se uma grande evolução, visto que os alunos já estavam mais familiarizados e com mais autonomia no uso computador. Os monitores aplicaram uma avaliação final relacionada à aprendizagem de forma prática, na qual os alunos enviaram e-mail aos professores e monitores, expondo suas autoavaliações perante as oficinas, conforme o depoimento de um dos participantes" [...] ]eu gostei de ter participado do curso Inclusão Digital. Aprendi a usar o computador com mais desempenho, usando o teclado, o mouse, fazer texto, salvar arquivos, enviar email, a usar o pen drive... só tenho a agradecer pelo conhecimento que levarei comigo." A maioria dos alunos mencionou que o medo de acessar foi dando lugar à confiança e busca pela prática em equipamentos que possuíam em suas residências.

Ao término do projeto, a turma encerrou com vinte e dois concluintes, sendo que cada participante faz jus à certificação da carga horária total de setenta horas.

\section{CONCLUSÕES}

Este artigo descreve os esforços dos autores, implementados através de um projeto de inclusão digital para adultos, no sentido de viabilizar a inclusão digital para alunos com o perfil escolhido, residentes em cidades da região da Associação dos Municípios da região de Laguna-AMUREL.

A importância do projeto consiste no fortalecimento de uma sociedade da informação mais igualitária, na qual o acesso às tecnologias digitais de informação e comunicação seja mais igualitário, favorecendo a inclusão digital, social e profissional dos alunos.

Nesse sentido, o projeto oportunizou aos participantes um ambiente de troca de conhecimento, experiências e de interação. Assim, as atividades desenvolvidas fortaleceram nos alunos a crença na sua capacidade de lidar com os recursos digitais, desmistificando essas tecnologias, e ao mesmo tempo permitindo a eles, expandir o olhar para novas possibilidades, tanto pessoais como profissionais. Isto foi possível já que o projeto teve um forte apelo social, permitindo fortalecer a importância de se pensar e de atuar em prol da cidadania, contribuindo para o desenvolvimento socioeconômico de comunidades e promovendo a inserção significativa do público atendido nas diversas situações de interação social e profissional por meio da autonomia no uso do computador.

Por outro lado, o desenvolvimento do projeto também permitiu aos alunos bolsistas fortalecerem sua autoestima e segurança em relação aos recursos digitais, além de tomarem conhecimento das etapas envolvidas na elaboração de um projeto.

Finalmente, em relação ao IFSC, o projeto está fortemente alinhado com a missão da instituição, que tem como objetivo promover a inclusão e formar cidadãos. 


\section{REFERÊNCIAS}

ASSMANN, Hugo. A Metamorfose do aprender na sociedade da informação. Ciência da Informação. Brasília, 2000, v.29, n.2, p.7-15. Disponível em: 〈https://www.scielo.br/pdf/ci/v29n2/a02v29n2.pdf >. Acesso em: 19 Dez. 2017.

\section{CENTRO REGIONAL DE ESTUDOS PARA O DESENVOLVIMENTO DA SOCIEDADE DA}

INFORMAÇÃO. TIC Domicílios 2016. São Paulo: Cetic.br, 2016. Disponível em: <http://www.cetic.br/ pesquisa/domicilios/indicadores >. Acesso em: 19 Dez. 2017.

FREIRE, Paulo. Pedagogia da autonomia: saberes necessários à prática educativa. São Paulo: Paz e Terra, 1996.

FREIRE, Isa Maria. O desafio da inclusão digital. Transinformação, v. 16, n. 2, 9 ago.2012. Disponível em: <http://periodicos.puccampinas.edu.br/seer/index.php/transinfo/article/view/720 >. Acesso em: 19 Dez. 2017.

INSTITUTO FEDERAL DE EDUCAÇÃO, CIÊNCIA E TECNOLOGIA DE SANTA CATARINA(IFSC). Plano de Desenvolvimento Institucional, 2020. Disponível em: <https://www.ifsc.edu.br/documentosnorteadores>. Acesso em: 01 Abr. 2021.

LAZARTE, Leonardo. Ecologia cognitiva na sociedade da informação. Ciência da informação, Brasília, v.29, n.2, p.43-51, 2000. Disponível em: <https://www.scielo.br/pdf/ci/v29n2/a06v29n2> Acesso em: 01 Abr. 2021.

THE ECONOMIST. The inclusive internet index: bridging digital divides, intelligence unit, 2017. Disponível em: 〈https://theinclusiveinternet.eiu.com/assets/external/downloads/3i-bridging-digital-divides.pdf > Acesso em: 19 dez. 2017.

Submetido em: 08/02/2021 Aceito em: 14/04/2021. 